\title{
NBSIR 75.739
}

\section{Development of Specifications for Archival Record Materials}

W. K. Wilson and E. J. Parks

Paper Evaluation Section Institute for Materials Research National Bureau of Standards

June 30,1975

Annual Report

Prepared for

National Archives and Records Service

Washington, D. C. 20408 
NBSIR 75-739

\section{DEVELOPMENT OF SPECIFICATIONS FOR} ARCHIVAL RECORD MATERIALS

W. K. Wilson and E. J. Parks

Paper Evaluation Section

Institute for Materials Research

National Bureau of Standards

June 30,1975

Annual Report

Prepared for

National Archives and Records Service

Washington, D. C. 20408

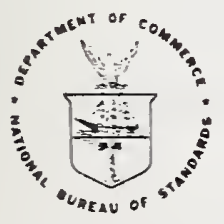

U.S. DEPARTMENT OF COMMERCE, Rogers C.B. Morton. Secretary

NATIONAL BUREAU OF STANDARDS, Richerd W. Roberts, Diroctor 
. 


\section{Contents}

1. Summary 1

2. Background 2

3. Objectives 3

4. Completed Specifications 4

5. Evaluation of Stability of Copies From 5 office Copying Machines

6. Accelerated Aging of Book Papers at $100^{\circ} \mathrm{C} \quad 6$ Compared with 36 Years Natural Aging

7. Study of Uncoated Book Papers After 10 Years of Natural Aging

8. Sorption of Oxygen by Papermaking Pulp 10

9. Accelerated Aging of Handsheets at $90^{\circ} \mathrm{C} \quad 11$ and Various Relative Humidities

10. Modification of pH Tests

11. Effects of Iron and Magnesium on Alkaline 13 Peroxidation of Carbohydrates

12. Status of Reports and Manuscripts 14

13. Plans for the Period July 1, 1975- 15

October 1, 1976

14. References 


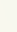




\section{Summary}

Progress during FY-1975 on a long range program on the Development of Specifications for Archival Record Materials includes the following:

(1) Report NBSIR 74-501 entitled An Analysis of the Aging of Paper: Possible Reactions and Their Effects on Measurable Properties. Although dated April 26, 1974, this was not included as a completed task in the annual report for $F Y-1974$.

(2) Report NBSIR 74-498(R) entitled Evaluation of Archival Stability of Copies From Representative Office Copying Machines. Although dated April 30, 1974, this was not issued until much later and was not included as a completed task in the annual report for FY-1974.

(3) Report NBSIR 74-632, Comparison of Accelerated Aging of Book Papers in 1937 With 36 Years Natural Aging.

(4) A specification for copies from offical copying machines for permanent records has been carried through the task group stage and the subcommittee stage in the ASTM standards process.

(5) A modification of the standard method. for determination of $\mathrm{pH}$ of paper has been developed.

(6) Considerable progress has been made on evaluation of the effect of relative humidity on the aging of paper. The effect of moisture at higher relative humidities is so great that it appears that a low relative humidity would be desirable for accelerated aging.

(7) Work on oxygen sorption during aging is inconclusive. 


\section{Background}

In response to a request by the National Archives and Records Service, the National Bureau of Standards is developing information on the variables associated with the stability of archival record materials, especially paper. Several U. S. Government agencies and the Society of American Archivists have joined in sponsorship of the project through National Archives and Records Service.

Many record materials of archival or long-term historical value in repositories in the Federal Government and throughout the United states are in bad physical condition. If proper specifications were available for materials that are designed to be used for permanent records, future problems concerned with the deterioration of record materials and the cost of repairing the mistakes of the past would be greatly diminished.

Much of the earlier work on this project was directed toward the development of an accelerated aging method. As this is a long-range effort, in terms of time and scope, and as archivists and librarians need specifications today for record materials, interim specifications based on $\mathrm{pH}$ requirements have been prepared for selected materials. Work on an accelerated aging method is continuing, and substantial progress has been made during FY-1975. 
3. Objectives

The objectives of this program are as follows:

(1) The development of information on the stability of paper and other record materials.

(2) The development of test methods for the evaluation of the stability of paper and other record materials.

(3) The development of specifications for materials suited for permanent records. 
4. Completed Specifications

The following specifications have been cleared through the American Society for Testing and Materials (ASTM):

D-3208, Standards Specification for Manifold Papers for Permanent Records. This specification appears in Part 20 of the 1975 ASTM Book of Standards. It also is available from ASTM as a single reprint.

D-3290, Standard Specification for Bond and Ledger Papers for Permanent Records. This specification is available as a single reprint, and it appears in the 1975 ASTM Book of Standards.

D-3301, Standard Specification for File Folders for Storage of Permanent Records. This specification is available as a single reprint, and it appears in the 1975 ASTM Book of standards.

These specifications have been approved by the American National Standards Institute (ANSI) as ANSI standards. 
5. Evaluation of Stability of Copies From office Copying Machines

Technology has provided over the past 20 years a plethora of machines for making copies of originals by pressing a button. As some of these copies have not proven to be particularly stable, and as these copies have found their way into permanent record files in various organizations, specifications for this type of copy are urgently needed. paper must be capable of being transported through the copying machine for which it is intended. The paper may be plain, coated, or impregnated, and supplies may be purchased from sources other than the suppliers of the copying machines. As $\mathrm{pH}$ can be used as a sole criterion of probable longevity only for plain uncoated paper, an accelerated aging method is required. The only official accelerated aging method for paper involves oven aging for 72 hours at $105^{\circ} \mathrm{C}$. In addition, stability of the image must be evaluated.

Representative samples were obtained from several manufacturers and tested in order to obtain the data necessary for preparing specifications for the paper and for stability of the image. This work has been completed and reported [1]. The specification is based on: (1) minimum pH requirement, (2) minimum retention of tear and fold after accelerated aging, and (3) retention of reflectance of image after exposure to a xenon arc and after abrasion by a standard technique.

The specification has been approved by the ASTM Task Group on office Copy Papers for Permanent Records and by ASTM D06.20, Paper for Permanent Records. It has been balloted by ASTM D-06, Paper, and a few negative ballots must be resolved. It should be possible to complete the work within 6 months. 
6. Accelerated Aging of Book Papers at $100^{\circ} \mathrm{C}$ Compared with 36 Years Natural Aging

In 1937 a group of book papers made in the NBS paper mill was tested before and after accelerated aging for 72 hours at $100^{\circ} \mathrm{C}$. Although there was no plan to test these papers after natural aging, a collection of some of these papers had been kept in an office for several years. The manufacturing history was known and the physical and chemical properties had been extensively evaluated for that time. Out of a total 72 papers, 18 were found that could be assembled to form a reasonably coherent set of samples.

The fiber compositions fall into three categories: (1) 50-50 soda-sulfite, (2) purified wood pulp, and (3) old rag. Chemically, these papers are very different. The sodasulfite papers contain a high percentage of hemicelluloses, the purified wood pulps are low in hemicelluloses, and the rag papers contain no hemicelluloses. The hemicelluloses are more vulnerable to degradation than cellulose.

The following conclusions may be drawn from the data obtained on these papers [2]:

(1) The changes in alpha cellulose that occurred during accelerated aging for three days at $100^{\circ} \mathrm{C}$ correlated well with changes in alpha cellulose that occurred after 36 years of natural aging. Alpha cellulose, or perhaps some more convenient alkali solubility method, should be suitable as a criterion of resistance to accelerated aging.

(2) The same is true for copper number.

(3) Correlations of retention of folding endurance after natural and accelerated aging were fair only. Although fold is useful as an evaluation method after accelerated aging, one should not rely on it completely.

(4) Correlations of internal tear after natural and accelerated aging were somewhat better than for folding endurance, but still not great.

(5) Correlations between cold extract pH in 1937 and changes after natural aging in alpha cellulose, copper number, fold, tear, and elongation indicate that $\mathrm{pH}$ is a reasonably good criterion of stability. 
(6) Retention of tear after natural aging correlated well with retention of elongation after natural aging.

(7) Retention of fold after natural aging correlated fairly well with elongation after natural aging, but not as well as tear and elongation.

(8) Corrlation between $\mathrm{pH}$ and zero span tensile data for all 18 papers was very poor, but when the data were separated into statistically homogeneous subsets, the correlations were better.

(9) The correlation between $\mathrm{pH}$ and breaking load of wet paper as a percent of breaking load when dry for the 18 samples was fair only. When the data were separated into statistically homogeneous subsets, the correlations were better.

(10) The correlation between $\mathrm{ph}$ and energy at break for wet paper was fair only.

(11) The correlation between $\mathrm{pH}$ and extensional stiffness for wet paper was very poor. When the data were separated into statistically homogeneous subsets, the correlations were fair.

(12) It appears that $\mathrm{pH}$, and changes in alkali solubility, reducing power (copper number) and tearing strength after accelerated aging for 72 hours at $100^{\circ} \mathrm{C}$ are reasonable indications of stability. Fold is sensitive, but not as useful.

(13) Although changes after accelerated aging are not available, it appears from data after natural aging that zero span tensile and strength when wet as a percent of strength when dry should be useful criteria.

(14) When data in this report are compared with data in earlier reports, it appears that dry accelerated aging more nearly corresponds to natural aging than accelerated aging at 50 percent relative humidity. The data indicate, however, that some moisture should be present.

Although this experiment is not at all ideal, it probably represents the best control over samples and experimental conditions ever reported on a comparison of natural aging and accelerated aging. 
Most accelerated aging has been carried out in dry atmospheres, except that which has been directed towards evaluation of brightness reversion. Work in this laboratory has shown that significant differences exist between moist accelerated aging and dry accelerated aging [3, 4, 5]. Therefore, it is desirable to obtain as much test data as possible on papers that are still available that were subjected to accelerated aging several years ago. 
7. Study of Uncoated Book Papers After 10 Years of Natural Aging

The data from this group of papers are disappointing, and it is unlikely that a useful report can be written. The papers are too heterogeneous and not enough is known about them to be able to connect cause and effect. If time permits, another attempt will be made, but the situation is not encouraging. 


\section{Sorption of Oxygen by Papermaking Pulp}

It has been shown in earlier reports $[3,4,5]$ that the degradation of paper is influenced by both oxygen and moisture. Oxygen sorption is an easy experiment to run in the laboratory, as the set-up requires little attention once it is placed in operation. Several sorption experiments were initiated in which tubes containing papermaking pulp were filled with humidified oxygen and placed in constant temperature baths at temperatures ranging from $50^{\circ}$ to $90^{\circ}$.

The data obtained so far are inconclusive. The experimental conditions appear to determine whether oxygen is sorbed or gases are evolved. At $90^{\circ} \mathrm{C}$ the pulp discolors badly and a brownish liquid collects in the bottom of the aging vessel. The work is continuing. 
9. Accelerated Aging at $90^{\circ} \mathrm{C}$ and Various Relative Humidities

Work on the accelerated aging of laboratory handsheets at N.B.S. has employed a temperature of $90^{\circ} \mathrm{C}$ with Air or nitrogen at 508 or 0 o relative humidity. Comparisons of data obtained after natural aging with those data obtained after accelerated aging under these conditions suggested that neither of these extremes in relative humidity approximated, in key processes, the changes to be expected in natural aging. A relative humidity of 508 appears to promote hydrolytic decomposition too rapidly, whereas dry aging promotes ccosslinking reactions to an extent that is out of proportion with the occurrance of crosslinking in natural aging. So it was felt that some intermediate relative humidity might be more desirable if accelerated aging at a high temperature were to be feasible.

Paper prepared from deeshed pulp has now been aged for periods up to 24 days at $90^{\circ} \mathrm{C}$ and $0 \%, 5 \%, 20 \%$ and $50 \%$ relative humidity to assess the aging effects of increasing amounts of moisture.

Tests have been conducted to determine changes in folding endurance, tearing resistance, trightness, moisture regain, pH, alpha cellulose, and copper number. Further tests will include determination of zero span tensile strength, dry and wet tensile properties, and probably some thermoanalytical properties, but these tests must await the availability of instruments.

The work completed so far shows that rates of change in the physical and chemical properties are highly dependent on relative humidities.

The data are incomplete, but it already is clear that extended aging at 50 percent relative humidity is not desirable. Although 20 percent relative humidity as an aging condition might be acceptable, it appears that a lower figure would be better. 


\section{Modification of $\mathrm{pH}$ Tests}

In the course of many pH determinations in this laboratory, it was observed that $\mathrm{pH}$ readings decreased slightly 10.1 to $0.2 \mathrm{pH}$ unit) if paper in suspension came into light contact with the reference electrode, and further decrease could be obtained if close contact was deliberately effected. Even if one is aware of this effect, it is sometimes difficult to avoid. Inspection of data obtained in the interlaboratory testing program conducted by NBS, suggested that the effect may commonly interfere with $\mathrm{pH}$ tests and should be avoided by making tests on decanted solvents. A manuscript on this topic is being prepared. 
11. Effects of Iron and Magnesium on Alkaline peroxidation of carbohydrates

Since January 1, 1975, E. J. Parks has been conducting research at American University, under the direction of Dr. Horace S. Isbell, on the mechanism of the alkaline peroxidation of carbohydrates, its acceleration by ferrous and ferric ions in solution, and its retardation by magnesium ions. These studies will in part comprise the topic of Parks' PhD dissertation. Magnesium ions are useful for reducing cellulose depolymerization during commercial bleaching processes with hydrogen peroxides, possibly because they form unreactive complexes with ions that promote the decomposition of hydrogen peroxide into reactive free radicals. The relation to paper permanence is quite speculative. However, as indicated in NBSIR 74-499, the formation of hydrogen peroxide in small amounts may also occur during the oxidative aging of paper. Methods for preventina the decomposition of $\mathrm{H}_{2} \mathrm{O}_{2}$ in catalytic amounts may consequently be of interest. from the permanence standpoint. 
12. Status of Reports and Manuscripts

(1) NBSIR 74-499 An Analysis of the Aging of Paper: Possible Reactions and Their Effects on Measurable Properties. Dated April 20, 1974, but report was not issued until much later.

(2) NBSIR 74-498 Evaluation of Archival Stability of Copies From Representative office Copying Machines. This includes a draft specification. Dated April 30, 1974, but report was not issued until much later.

(3) NBSIR 74-632 Accelerated Aging of Book Papers for 72 Hours at $100^{\circ} \mathrm{C}$ Compared with 36 Years Natural Aging. Issued December 18, 1974.

(4) Accelerated Aging of Commercial Book Papers at $90^{\circ} \mathrm{C}$ and 50 Percent Relative Humidity Compared with 10 Years Natural Aging. The testing of these papers is completed, but it does not appear that the data are of sufficient value to warrant a report.

(5) A Review of Accelerated Aging of Laboratory Handsheets. This was to be a review of three earlier NBS reports, 10627 , 10628 , and 10687 . It was hoped that a review of the data in these reports coupled with data obtained on the naturally aged papers would enable some conclusions to be drawn concerning an accelerated aging test. Much of the data from these three reports was included in NBSIR 74-632, so the need for a separate report is not now so pressing. If time permits, however, it will be written.

(6) Sorption of Oxygen by Papermaking Pulps. Data for this report are incomplete.

(7) Accelerated Aging of Handsheets at $90^{\circ} \mathrm{C}$ and Various Relative Humidities. This is partly written, but more data are needed. 
13. Plans for the Period July 1, 1975October 1, 1976

The following tasks will receive top priority:

(1) Accelerated aging of handsheets at several temperatures and at low relative humidities.

(2) Sorption of oxygen by papermaking pulp in humidified oxygen atmospheres.

(3) Finalize the specification on Copies from office Copying Machines for Permanent Records.

The following tasks will be pursued if time permits:

(1) Study of old papers in order to determine what actually happens during the aging of paper.

(2) Finalize a revision of the method for determination of the $\mathrm{pH}$ of paper.

(3) Complete the report on a review of earlier reports on aging of handsheets, NBS Reports number 10627, 10628 and 10687 .

(4) Complete the report on the study of uncoated book papers after 10 years of natural aging. This has a low priority. 
14. References

1. Parks, E. J. and Wilson, W. K., Evaluation of Archival Stability of Copies from Representative office Copying Machines, NBSIR 74-498(R).

2. Wilson, W. K. and Parks, E. J. Comparison of Accelerated Aging of Book Papers in 1937 with 36 Years Natural Aging, NBSIR 74-632.

3. Parks, E. J. and Hebert, R. L., Accelerated Aging of Laboratory Handsheets: Changes in Acidity, Fiber Strength, and Wet Strength, NBS Report No. 10627.

4. Parks, E. J. and Hebert, R. L., Accelerated Aging of Laboratory Handsheets: Retention of Folding Endurance, Internal Tear, Bursting Strength, and Tensile Strength, NBS Report No. 10628.

5. Parks, E. J. and Hebert, R. L., Accelerated Aging of Laboratory Handsheets: Reflectance, Moisture Regain, Sonic Modulus, and Differential Thermal Analysis, NBS Report No. 10687. 
* 



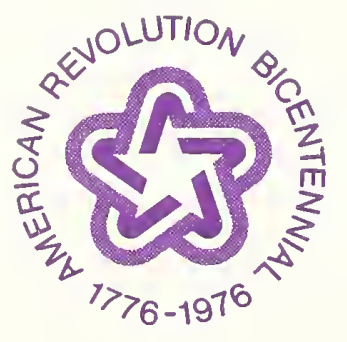

